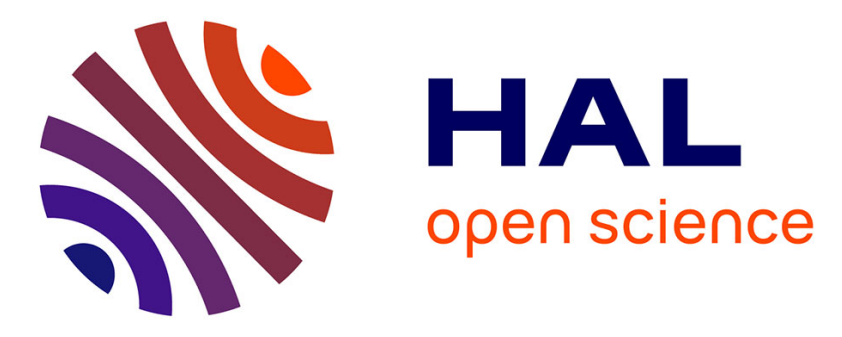

\title{
Plastic scintillators modifications for a selective radiation detection
}

\author{
Matthieu Hamel, Guillaume H. V. Bertrand, Frédérick Carrel, Romain \\ Coulon, Jonathan Dumazert, Eva Montbarbon, Fabien Sguerra
}

\section{To cite this version:}

Matthieu Hamel, Guillaume H. V. Bertrand, Frédérick Carrel, Romain Coulon, Jonathan Dumazert, et al.. Plastic scintillators modifications for a selective radiation detection. 2015 4th International Conference on Advancements in Nuclear Instrumentation Measurement Methods and their Applications (ANIMMA), Apr 2015, Lisbon, Portugal. pp.7465496, 10.1109/ANIMMA.2015.7465496 . cea01823369

\section{HAL Id: cea-01823369 https://hal-cea.archives-ouvertes.fr/cea-01823369}

Submitted on 16 Jul 2019

HAL is a multi-disciplinary open access archive for the deposit and dissemination of scientific research documents, whether they are published or not. The documents may come from teaching and research institutions in France or abroad, or from public or private research centers.
L'archive ouverte pluridisciplinaire HAL, est destinée au dépôt et à la diffusion de documents scientifiques de niveau recherche, publiés ou non, émanant des établissements d'enseignement et de recherche français ou étrangers, des laboratoires publics ou privés. 


\title{
Plastic scintillators modifications for a selective radiation detection
}

\author{
Matthieu Hamel,* Guillaume H.V. Bertrand, Frédérick Carrel, Romain Coulon, \\ Jonathan Dumazert, Eva Montbarbon, Fabien Sguerra
}

CEA, LIST, Laboratoire Capteurs \& Architectures Électroniques, 91191 Gif-sur-Yvette cedex (France).

E-mail: matthieu.hamel@cea.fr

\begin{abstract}
Recent developments of plastic scintillators are reviewed, from January 2000 to August 2015. All examples are distributed into the main application, i.e. how the plastic scintillator was modified to enhance the detection towards a given radiation particle. The main characteristics of these newly created scintillators and their detection properties are given.
\end{abstract}

KEYWORDS: Materials for solid-state detectors; Scintillators and scintillating fibres and light guide 


\section{Contents}

\section{Introduction}

Optimization of alpha detection

\section{Optimization of beta detection}

\section{Plastic scintillators for gamma and $x$-rays spectrometry}

\section{Thermal neutron detection}

Fast neutron detection

\section{Conclusion}

\section{Introduction}

Protection of civilians and facilities against CBRN-E (Chemical, Biological, Radiological, Nuclear, and Explosives) threats represent a true challenge due to the constant increase of world's population movements. According to Dr. El Baradei (1997 - 2009 IAEA Director General), terrorists who are unconcerned about exposing themselves to radiation could easily conceal a source in a truck or a suitcase. "The danger of handling powerful radioactive sources can no longer be seen as an effective deterrent, which dramatically changes previous assumptions. [...] Security of nuclear and other radioactive material has taken on dramatically heightened [in IAEA's work] significance in recent years."

As an example, a dramatic story happened in late 2013 in Mexico, where a radioactive cobalt-60 source (3,000 Curies, $111 \mathrm{TBq})$ was stolen from its transportation truck. Fortunately, the material was safely recovered 8 days later [1].

In this context, numerous detectors could be used for NR detection. Among them, we will focus in this Review on plastic scintillators (hereafter abbreviated as PS, see footnote ${ }^{1}$ ). These materials can be defined as one or several fluorescent probes embedded in a polymer matrix, and the resulting system is able to produce light while interacting with a radioactive source (Figure 1 is an example produced with a UV lamp as excitation). For instance, a typical scintillation cocktail

\footnotetext{
1 Standard abbreviations used in this document: a-NPO: 2-(1-Naphthyl)-5-phenyloxazole; AIBN: aso-bisisobutyronitrile; BBO: 2,5-bis-(4biphenylyl)-1,3,4-oxadiazole; CL: Cathodoluminescence; CQD: carbon quantum dot; DVB: divinylbenzene; FOM: Figure Of Merit; HMPA: hexamethylphosphoramide; IBIL: Ion Beam Induced Luminescence; LiMA: Lithium Methacrylate; Li-Sal: Lithium Salicylate; MEH-PPV: Poly[2-methoxy-5-(2-ethylhexyloxy)-1,4-phenylene-vinylene; MPA : mercaptopropionic acid; MOF: Metal Organic Framework; NMP: 1methyl-2-pyrrolidinone; $p$-T: p-terphenyl; PBBO: 2-(4-biphenylyl)-6-phenylbenzoxazole; PBD: 2-(4-Biphenylyl)-5-phenyl-1,3,4-oxadiazole; PEG: poly(ethylene glycol); PL: Photoluminescence; PBMA: Poly(benzyl methacrylate); PMMA: Poly(methyl methacrylate); POPOP: 1,4Bis(5-phenyl-2-oxazolyl)benzene; PPO: 2,5-Diphenyloxazole; PS: Plastic scintillator; PSD: Pulse shape discrimination; PSt: polystyrene; PVA: Polyvinyl alcohol; PVK: Polyvinylcarbazole; PVT: Polyvinyltoluene; QD: Quantum dots; SEM: Scanning electron microscopy; SSD: Spectral shape discrimination; St: styrene, TTA: Triplet-triplet annihilation.
} 
is made from $p$-terphenyl and POPOP dissolved in polystyrene. The preparation of a plastic scintillator was first described in the late 50's [2].

To detect Special Nuclear Materials (roughly speaking, isotopes of uranium and plutonium), plastic scintillators present several advantages. They are cheap (especially interesting for large size detection systems), sensitive to gamma-rays, can be handled without any specification, reliable, stable and can be prepared in large volumes. More particularly, the choice of the detector will become extremely important in the future due to the combination of the cheapness of PS (\$ 2,000 for a $3.8 \mathrm{~cm} \times 36 \mathrm{~cm} \times 173 \mathrm{~cm}$ large PVT detector, compared to $\$ 6,000$ for a $5 \mathrm{~cm} \times 10$ $\mathrm{cm} \times 41 \mathrm{~cm} \mathrm{NaI}(\mathrm{Tl})$ inorganic scintillator [3]) and the necessity for some countries to cover at the best their borders with radiation portal monitors.

But some drawbacks have incited several groups to renew with chemical developments of plastic scintillators: they display a poor resolution, were presumed for a long time to be unable to perform fast neutron/gamma discrimination, afford relative low scintillation yields compared with inorganic scintillators and cannot give access to the full energy of an incident gamma.

The most relevant examples will be described in the following sections, which are distributed as a function of the optimization of the PS towards the nature of the ionizing radiation. The Reader is encouraged to refer to the full Review about this topic [4]. Also, this Review is exclusively limited to plastic scintillators and derivatives (composites, sol-gel, etc.). No data will be given regarding improvements on organic single crystals, optical (scintillating) fibres, liquid scintillators and inorganic scintillators.

\section{Optimization of alpha detection}

The detection of alpha-emitting radionuclides is always a big challenge, due to the fact that they are highly ionizing and heavy particles. They interact within a few micrometres (e.g. an alpha of energy $5 \mathrm{MeV}$ will penetrate within $35 \mu \mathrm{m}$ in polystyrene). Contrarily, a $1 \mathrm{MeV}$ gamma would need not less than $14 \mathrm{~cm}$ and a $1 \mathrm{MeV}$ electron $4.3 \mathrm{~mm}$ to fully release their energy.

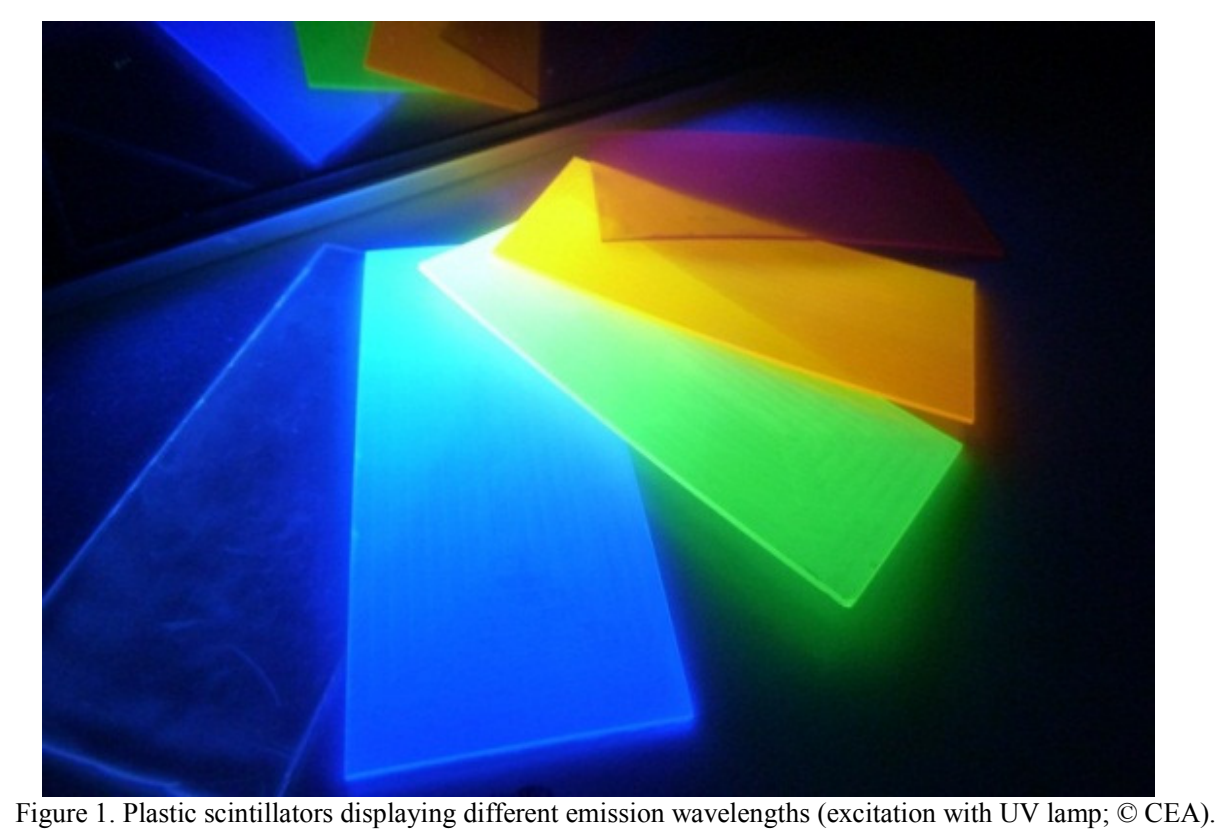


In this context, it is noteworthy the work performed by Tarancón et al. for the replacement of liquid scintillators with scintillating microspheres. Contrary to the former, PS microspheres do not generate mixed wastes after the measurement and are particularly suitable for alpha and beta emitters. Scintillation properties of microspheres prepared from PSt doped with various, classical fluorophores: $p$-terphenyl, PPO, POPOP, bis-MSB and naphthalene, with a typical diameter of ca. $130 \mu \mathrm{m}$ were investigated [5].

Although sol-gel materials can be considered as inorganic structures, one has to admit that they are prepared from organic molecules. Also, as they are usually prepared in the form of small monoliths, their size is suitable for alpha measurements. Thus, thin layer scintillators were prepared from various silicates, PPO and POPOP [6]. A modest detection was observed.

\section{Optimization of beta detection}

Beta detection can also be performed with microspheres, via an alpha/beta discrimination process [5]. Even low-energy beta emitters such as ${ }^{3} \mathrm{H}$ and ${ }^{14} \mathrm{C}$ are detected via scintillation counting. An optimized diameter size was determined for each radionuclide. Detection efficiency values obtained with these synthesized microspheres for ${ }^{3} \mathrm{H},{ }^{14} \mathrm{C},{ }^{90} \mathrm{Sr} /{ }^{90} \mathrm{Y}$ and ${ }^{241} \mathrm{Am}$ sources are better than those obtained using commercial plastic scintillation microspheres (from Saint-Gobain or Detec-Rad).

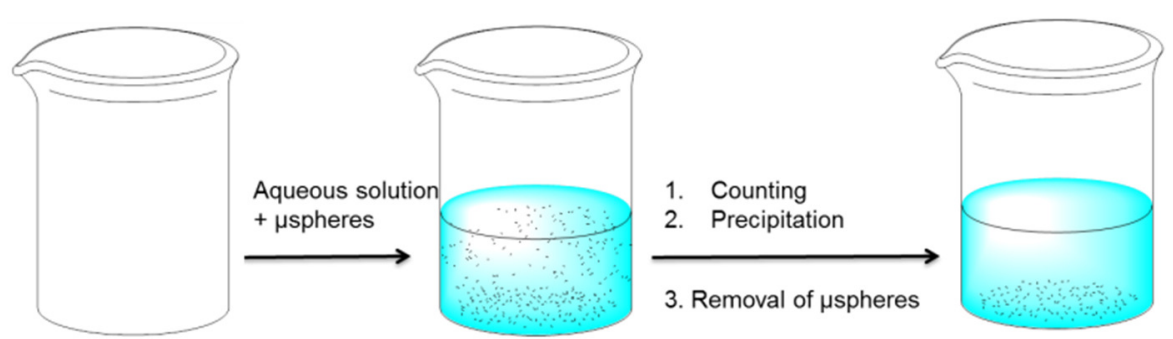

Figure 2. Experimental method for scintillation counting with scintillating microspheres.
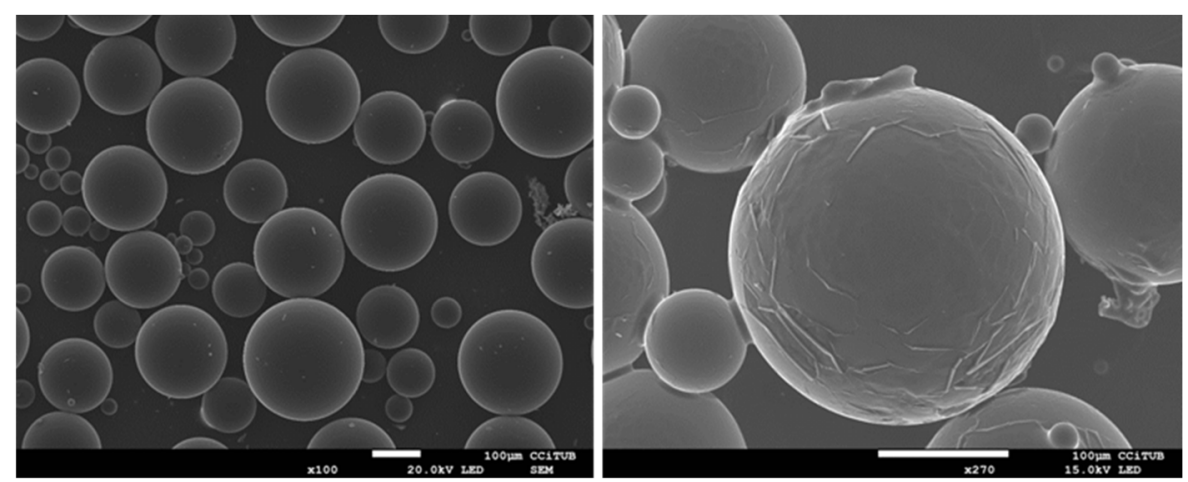

Figure 3. SEM picture of scintillating microspheres (C A. Tarancón, with permission). 

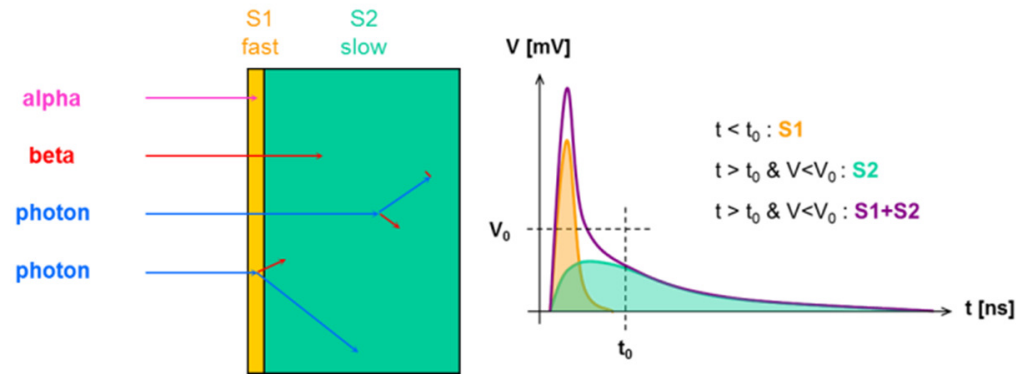

Figure 4. Principle of beta/gamma discrimination using phoswich scintillators.

Another approach using standard size plastic scintillators is based on the phoswich principle. Whereas the electron can deposit its energy in the first (mainly) and the second scintillator, the gamma background will impact both layers, accordingly with their respective volumes. Thus, by comparing the scintillation pulse profiles of the thin - and fast - and the thick - and slow - plastic scintillators, one may discriminate beta from gamma rays [7]. Moreover the two scintillating layers were coupled altogether without glue so as to give access to the full beta energy peak.

\section{Plastic scintillators for gamma and x-rays spectrometry}

An important modification of the composition of a plastic scintillator is to make it denser and to increase its effective $Z\left(Z_{\text {eff }}\right)$ by heavy metal loading. But heavy atoms tend to have a strong fluorescence quenching due to multiple vibrational relaxations. Nevertheless a compromise can be found between higher absorption and lower light output, so as to lead to a pseudo-gamma spectrometry.

Currently most of the developments use tin, lead and bismuth organometallics, and more particularly the two latter metals. Lead, in its lead dimethacrylate form, has been extensively studied these years at the CEA [8] and the loaded plastic scintillator has been implemented for the Laser Mégajoule facility as a hardened imaging system for $10-40 \mathrm{keV} \mathrm{X-rays} \mathrm{[9].} \mathrm{Concerning} \mathrm{gamma-rays} \mathrm{identification,} \mathrm{the} \mathrm{best} \mathrm{results} \mathrm{are}$ obtained with bismuth(III) organometallics as dopants. Triphenyl bismuth, triaryl $[10,11]$ and tricarboxyl bismuth complexes $[10,12]$ have been reported. With such loading, the apparition of the photoelectric peak was observed for high energy X-rays and gamma below $200 \mathrm{keV}$, as well as in synchrotron conditions [13] by several groups around the world. PE Peak was also claimed to be observable with a ${ }^{137} \mathrm{Cs}$ source $(662 \mathrm{keV})[12]$. It is noteworthy that some other exotic metals such as hafnium of zirconium - in a nanoparticle form - have also been studied to enhance x-rays detection [14].

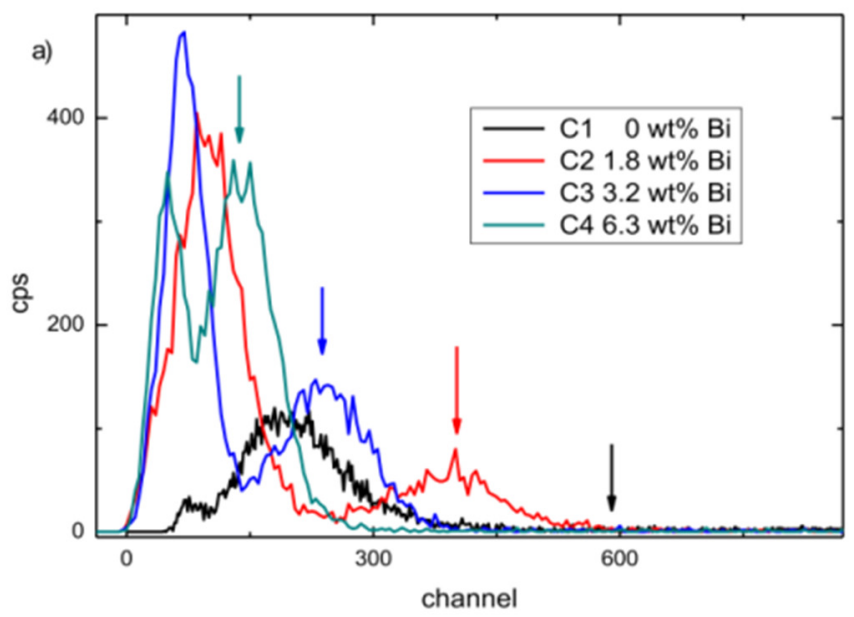

Figure 5. Pulse area spectra of compounds 1 to 4 displaying various $\mathrm{BiPh}_{3}$ loadings when exposed to a ${ }^{57} \mathrm{Co}$ gamma source $(0.9$ $\mathrm{kBq}$ ). The arrow shows the full energy peak at $122.1 \mathrm{keV}$. 


\section{Thermal neutron detection}

Neutron detection is of primarily importance since the shortage of ${ }^{3} \mathrm{He}$, the most important neutron absorber for homeland security applications. In this context, several helium-3 alternatives are required. Absorption of thermal neutrons (generated after multiple collisions with hydrogen atoms) is not natural for a standard plastic scintillator and requires different elements other than $\mathrm{C}, \mathrm{H}, \mathrm{N}, \mathrm{S}$ or $\mathrm{O}$. The desired isotopes with large cross sections towards thermal neutrons are given in Table 1 with their natural abundances.

\begin{tabular}{|c|c|c|c|}
\hline Isotope & Reaction of interest & Thermal Cross section (Barns) & Isotope abundance \\
\hline${ }^{3} \mathrm{He}$ & ${ }^{3} \mathrm{He}+n \rightarrow{ }^{3} \mathrm{H}+1 \mathrm{H}+0.765 \mathrm{MeV}$ & 5,330 & $0.00013 \%$ \\
\hline${ }^{6} \mathrm{Li}$ & ${ }^{6} \mathrm{Li}+n \rightarrow{ }^{3} \mathrm{H}+\alpha+4.78 \mathrm{MeV}$ & 940 & $7.5 \%$ \\
\hline${ }^{10} \mathrm{~B}$ & ${ }^{10} \mathrm{~B}+n \rightarrow{ }^{7} \mathrm{Li} *+\alpha+2.8 \mathrm{MeV} \rightarrow{ }^{7} \mathrm{Li}+\alpha+\gamma(0.48 \mathrm{MeV})$ & 3,840 & $19.9 \%$ \\
\hline${ }^{113} \mathrm{Cd}$ & ${ }^{113} \mathrm{Cd}+n \rightarrow{ }^{114} \mathrm{Cd}+\gamma^{\prime} s(9 \mathrm{MeV})$ & 30,000 & $12.2 \%$ \\
\hline $\begin{array}{l}{ }^{155} \mathrm{Gd} \\
{ }^{157} \mathrm{Gd}\end{array}$ & ${ }^{155,157} G d+n \rightarrow{ }^{156,158} G d * \rightarrow{ }^{156,158} G d+e-+\gamma^{\prime} s(8 M e V)$ & $\begin{array}{l}60,700 \\
254,000\end{array}$ & $\begin{array}{l}14.7 \% \\
15.7 \%\end{array}$ \\
\hline
\end{tabular}

Boron-loaded plastic scintillators are very well documented as they are commercially available (BC-454 or EJ-254 from Saint-Gobain and Eljen Technology, respectively). Due to the low atomic number of boron, there is no gamma rays detection enhancement and the thermal cross section of $\mathrm{B}$ allows a moderate, yet efficient loading. Also, as the capture of the thermal neutron releases an alpha particle, pulse discrimination is therefore possible [15].

Usually the carborane molecule is used as dopant in the plastic scintillator series, thanks to its extremely high content of boron inside the whole molecule. However, the use of pyrene modified with pinacolyl borate on four positions [16]. The boron-rich pyrene (and benzene) derivatives are prepared by Suzuki conditions using both microwave and traditional heating, affording yields of $40-93 \%$. Plastic scintillators with boron loading as high as $5 \mathrm{wt} \%$ are thus obtained.

Lithium has been less studied due probably to the lower cross section and the highly diffusive nature of organolithium compounds. Recently several improvements have been reported, with the use of dopants such as lithium pivalate $\left[{ }^{17}\right]$ or lithium (phenyl)salicylate [18], or as co-monomers, in the form of lithium methacrylate [19] or lithium maleate [20] (Figure 7).

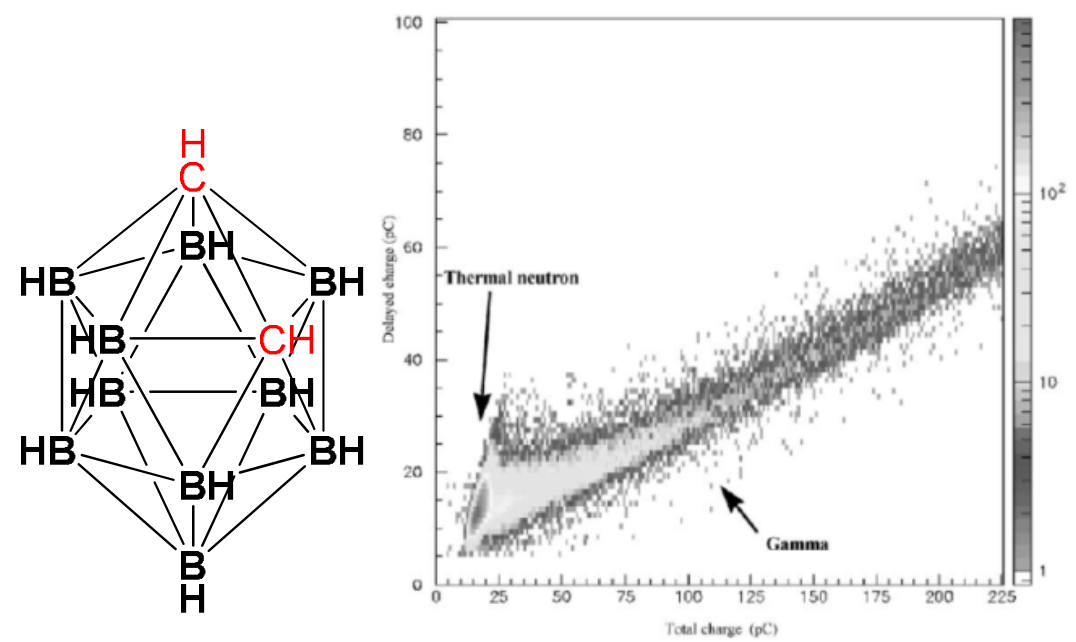

Figure 6. Left: structure of ortho-carborane; right: pulse shape discrimination spectrum between thermal neutrons and gamma rays. 


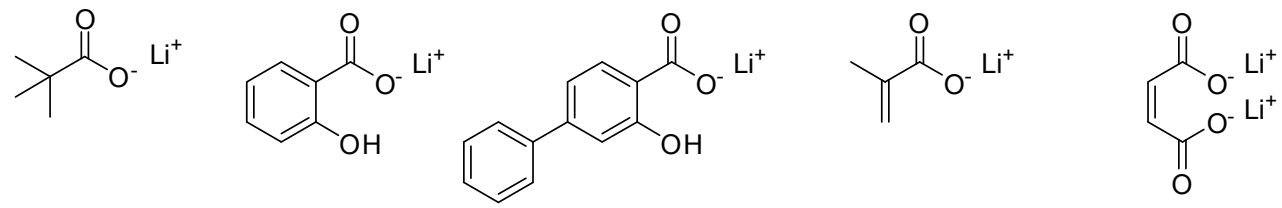

Figure 7. Lithium pivalate, lithium salicylate, lithium 4-phenylsalicylate, lithium methacrylate and lithium maleate.
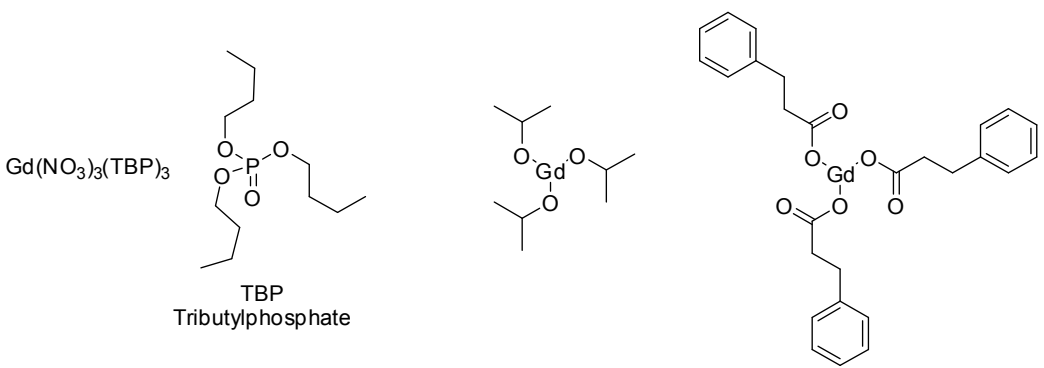

Figure 8. Examples of gadolinium-loaded compounds for potential incorporation into plastic scintillators: gadolinium nitrate tributylphosphate [21], gadolinium tris-isopropoxide [22], gadolinium tris-phenylpropionate [23].

To the best of our knowledge, cadmium loading in its organometallic form in PS- or PVTbased plastic scintillators has never been reported, due to the extreme toxicity of organocadmium compounds.

Last but not least, gadolinium presents the highest cross section of all stable elements, so only a low concentration of Gd is necessary within the scintillator for complete capture of the thermal neutron. Gadolinium is usually added in its organometallic form or as a salt chelated with a suitable phosphate. However, due to the release of electrons and gamma rays upon capture of the thermal neutron, pulse shape discrimination is not possible. But it is still possible to access to the neutron information by compensation [24] or by using the high-energy gamma rays signature emitted by neutron capture with $\mathrm{Gd}$ [25]. In this context, we have developed a scintillating sphere - so-called GADOSPHERE ${ }^{\mathrm{TM}}$ (Figure 9) - with detection performances close to a ${ }^{3} \mathrm{He}$-based Bonner sphere of same volume. This relocatable neutron detector presents characteristics as mentioned in the Table 2.

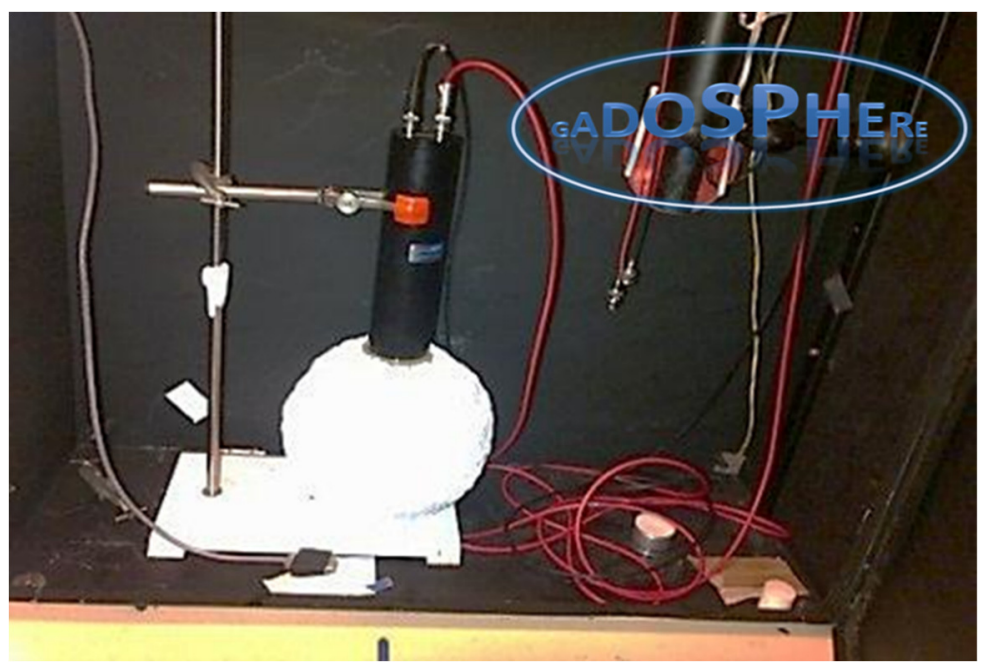

Figure 9. GADOSPHERE ${ }^{\mathrm{TM}}$ setup experiment. 
Table 2. Main characteristics of GADOSPHERE ${ }^{\mathrm{TM}}$ when exposed to a ${ }^{252} \mathrm{Cf}$ source, benchmarked with a Berthold LB6411 probe.

\begin{tabular}{|lll|}
\hline & GADOSPHERE & Berthold LB6411 \\
Sensitivity $\left(\mathrm{c} \cdot \mathrm{n}^{-1} \cdot \mathrm{cm}^{2}\right)$ & $0.77 \pm 0.13$ & $0.055 \pm 0.002$ \\
Limit of detection $\left(\mathrm{n} \cdot \mathrm{cm}^{-2} \cdot \mathrm{s}^{-1}\right)$ & $5.0 \pm 2.0$ & $2.4 \pm 0.8$ \\
Gammar background & 50 & 10000 \\
saturation $\left(\mu \mathrm{Sv} \cdot \mathrm{h}^{-1}\right)$ & & \\
\hline
\end{tabular}

\section{Fast neutron detection}

The main challenge for fast neutron detection is to dissociate their response from the gamma background. Unlike alpha or beta rays, neutrons have a scintillator penetration range similar to gamma. Only the ionization mechanism is slightly different between gamma and neutrons, and can produce some kind of signal discrepancy. Pulse Shape Discrimination (PSD) was early-on chosen as the technic of choice for observing, separating and attributing individual contributions coming either from a neutron or from a gamma [26].

It was assumed for a long time that plastic scintillators would be unable to efficiently perform PSD. But as early as 1960, Frank D. Brooks prepared a plastic scintillator suitable for fast neutron/gamma discrimination [27]. It was composed on 4-isopropylbiphenyl, a molecule which acted both as a primary fluorophore and "secondary solvent". Added at the concentration of $10 \mathrm{wt} \%$, along with $p$-terphenyl and POPOP inside PSt, it was later on commercialized by Nuclear Enterprise under the trade name NE-150. Unfortunately, the product was discarded after 6 months due to whitening and edge deforming (Figure 10).

Probably based on this preliminary work, different groups noticed that the triplet-triplet annihilation (TTA), which is at the genesis of $\mathrm{n} / \gamma$ PSD, was not probable enough in plastics compared with liquids [28]. Thus, by increasing drastically the loading of primary fluorophore, the probability of triplet-triplet interactions should increase. As their concentration goes up, the likelihood to have a precise overlap of orbitals between two fluorophores increases and they should be able to exchange more excitons, and therefore their triplet - triplet annihilation could occur more efficiently for PSD to be achieved. This assumption was successfully demonstrated with small, lab-scale radioactive sources such as ${ }^{252} \mathrm{Cf}$ or AmBe.

Another strategy consists in the use of triplet-harvesting fluorophores, i.e. integrating fluorophores able to produce light via their triplet state. In this context, organometallic, phosphorescent complexes are very promising chromophores for scintillation applications. An example of PSD achieved with an iridium complex in a polymeric matrix was described by Feng et al. [29]. The authors prepared a PVT polymer doped with the $0.1-0.2 \mathrm{wt} \%$ iridium complex $\operatorname{Ir}\left(\text { ppy- } \mathrm{F}_{2}\right)_{2}\left(\mathrm{~F}_{2}\right.$-pic). When ionized with an AmBe source, the scintillator shows a bi-exponential decay with a prompt and a delayed signal (respectively assigned to the gamma and fast neutrons response). In the same paper, the authors propose an unseen feature: spectral shape discrimination (SSD). 


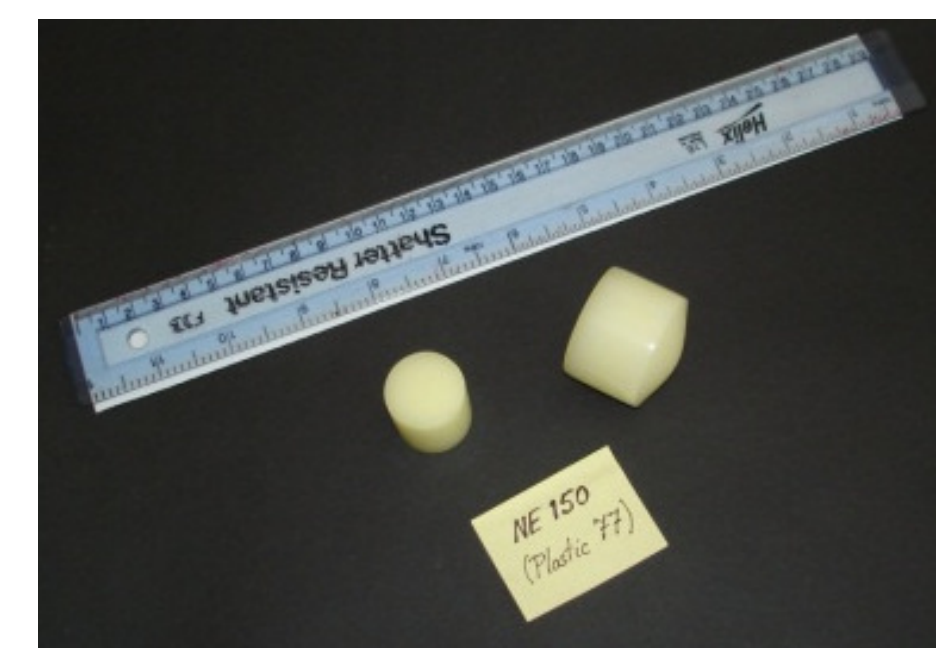

Figure 10; Picture of a degraded NE-150 plastic scintillator (@ F.D. Brooks, with permission).

On the same basis, the group of Adadurov reported twice the use of two different fluorophores in PS, one for collecting singlet states (1,4-dimethyl-9,10-diphenylanthracene, with addition of the wavelength shifter Luminophor 59: 1-phenyl-5-(4-methoxyphenyl)-3-(1,8naphthoenyl-1',2'-benzimidazole)-2-pyrazoline) and $\mathrm{Eu}(\mathrm{phen})(\mathrm{DBM})_{3}$ for collecting triplet states [30]. So herein the large decay time difference between the two dyes is exploited, as the singlet fluorophore displays a $13 \mathrm{~ns}$ decay time and the triplet fluorophore a $370 \mu \mathrm{s}$ decay time.

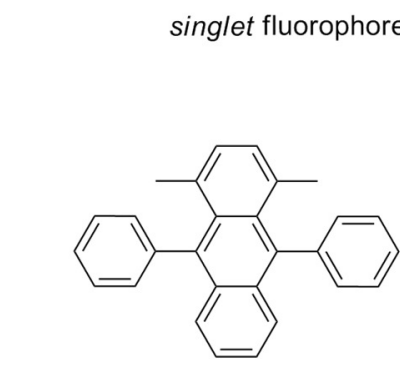

1,4-dimethyl-9,10-diphenylanthracene triplet fluorophore

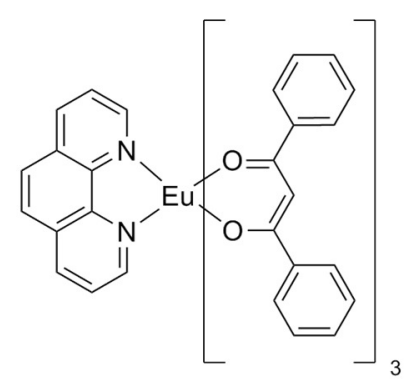

$\mathrm{Eu}(\mathrm{Phen})(\mathrm{DBM})_{3}$

Wavelength Shifter

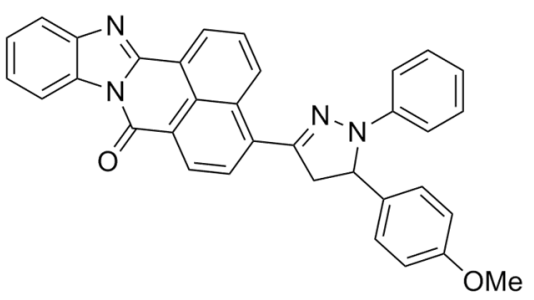

Luminophor 59

Figure 11. Representation of the singlet (with its wavelength shifter) and triplet fluorophores used by Adadurov et al. [30]. 
A collaboration between Polish and French teams has led to a proof-of-concept of fast neutron/gamma discrimination using the energy threshold of the reactions $\mathrm{n}\left({ }^{19} \mathrm{~F},{ }^{16} \mathrm{~N}\right) \alpha$ or $\mathrm{n}\left({ }^{19} \mathrm{~F},{ }^{19} \mathrm{O}\right) \mathrm{H}^{+}$for photofission prompt neutron detection [31]. Indeed, the energetic gap allows discriminating neutrons with $\mathrm{E}>2.5 \mathrm{MeV}$ with less energetic neutrons and gamma. To reach this, polystyrene has been replaced by poly(2,3,4,5,6-pentafluorostyrene). A very high density was observed (1.56), equal to the $\mathrm{Pb}$-loaded plastic scintillator cited before. Light output was estimated to be close to $3,100 \mathrm{ph} / \mathrm{MeV}$, with a decay time of $3.0 \mathrm{~ns}$, and preliminary results for $\mathrm{n} / \gamma$ discrimination of a PuBe radioactive source were somehow modest but exist (Figure 12), as due to small dimensions of the sample, energy deposition of highly energetic electron from beta decay of ${ }^{16} \mathrm{~N}$ and ${ }^{19} \mathrm{O}$ is weak.

\section{Conclusion}

To the best of our knowledge, modifying plastic scintillators for fast neutrons detection and discrimination is the most recent example of new material supplied by plastic scintillators manufacturer. Indeed, EJ-299-33 is a promising result for chemists who want to create new solutions for physicists. But still, the road is long for that product to respond to all criteria for Homeland Security applications for example.

Some other challenges are facing chemists; among others, the key of many problems is probably the increase of the resolution and the light yield of the detector, which should lead to many improvements on nuclear detection. Also, the scale up mandatory if these scintillators have to be used in radiation portal monitors, and both chemistry and photophysics issues have to be overcome.

\section{Acknowledgments}

We thank the French "Direction Générale de l'Armement" and "Secrétariat Général de la Défense et de la Sécurité Nationale" for the grant to GHVB. We also thank the "Agence Nationale de la Recherche" for the grant to FS. Finally, we would like to thank the Authors who accepted to allow the reproduction of figures or pictures.

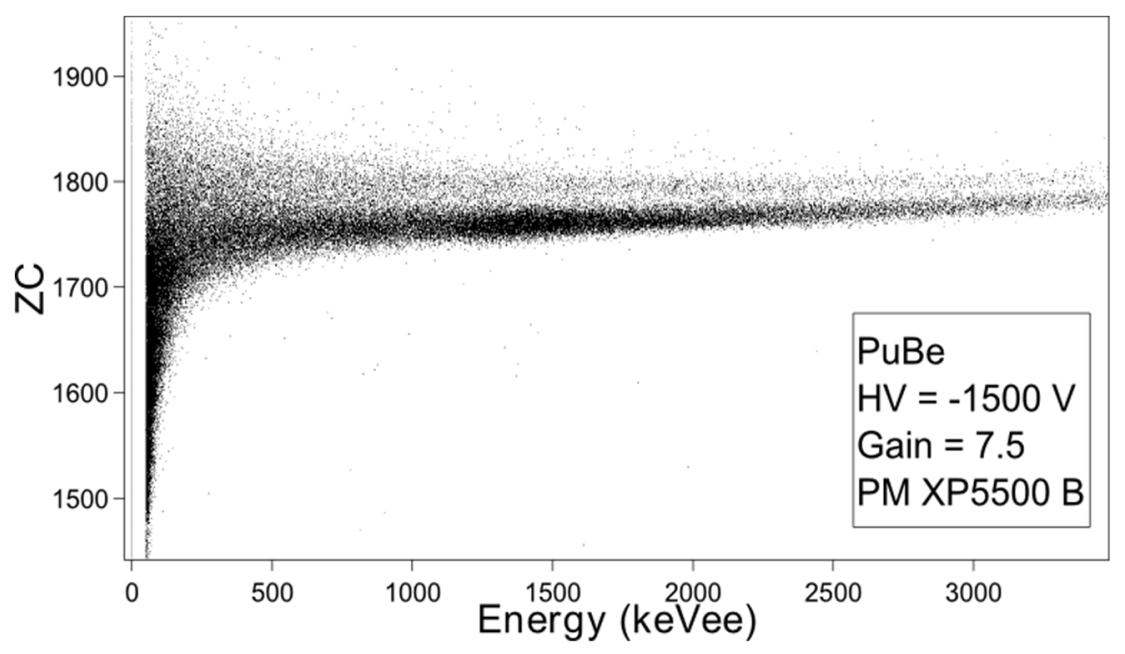

Figure 12. Neutron/gamma discrimination when irradiating the sample with a PuBe source. 


\section{References}

[1] http://www.iaea.org/newscenter/news/2013/mexicoradsource4.html

[2] M.G. Schorr, and F.L. Torney, Solid Non-Crystalline Scintillation Phosphors, Phys. Rev. 80 (1950) 474.

[3] D.C. Stromswold et al., Comparison of Plastic and NaI(Tl) Scintillators for Vehicle Portal Monitor Applications, IEEE Nucl. Sci. Symp. Conf. 2 (2003) 1065.

[4] G.H.V. Bertrand et al., Current status on plastic scintillators modifications, Chem. Eur. J. 20 (2014) 15660.

[5] L.M. Santiago et al., Synthesis of plastic scintillation microspheres: Alpha/beta discrimination, Appl. Radiat. Isot. 93 (2014) 18.

[6] H.-J. Im et al., Scintillators for Alpha and Neutron Radiations Synthesized by Room Temperature SolGel Processing, J. Sol-Gel Sci. Techn. 32 (2004) 117.

[7] a) M. Hamel et al., Détecteur à Scintillation et Procédé de Fabrication associé, French Patent Application FR2983310, 2011; b) V. Kondrasovs et al., Procédé de Traitement de Signal issu d'un Scintillateur phoswich et Détecteur à Scintillation associé, French Patent Application FR2983311, 2011.

[8] a) M. Hamel et al., Preparation and characterization of highly lead-loaded red plastic scintillators under low energy X-rays, Nucl. Instr. Methods A 660 (2011) 57; b) G. Turk et al., Development of an x-ray imaging system for the Laser Megajoule (LMJ), Rev. Sci. Instrum. 81 (2010) 10E509.

[9] A. Rousseau et al., Development of a hardened imaging system for the Laser MegaJoule, EPJ Web Conf. 59 (2013) 13006.

[10] G.H.V. Bertrand et al., Influence of bismuth loading in polystyrene-based plastic scintillators for low energy gamma spectroscopy, J. Mater. Chem. C 2 (2014) 7304.

[11] G.H.V. Bertrand et al., Understanding behavior of different metals in loaded scintillators: discrepancy between gadolinium and bismuth, J. Mater. Chem. C 3 (2015) 6006; corrected J. Mater. Chem. C 3 (2015) 7523.

[12] N.J. Cherepy et al., Bismuth-and lithium-loaded plastic scintillators for gamma and neutron detection, Nucl. Instr. Methods A 778 (2015) 126.

[13] M. Koshimizu et al., X-ray Detection Capabilities of bismuth-doped Plastic Scintillators, Jpn. J. Appl. Phys. 54 (2015) 102202.

[14] (a) Y. Sun et al., High-energy X-ray detection by hafnium-doped organic-inorganic hybrid scintillators prepared by sol-gel method, Appl. Phys. Lett. 104 (2014) 174104; (b) Y. Araya et al., Enhanced Detection Efficiency of Plastic Scintillators upon Incorporation of Zirconia Nanoparticles, Sens. Mater. 27 (2015) 255.

[15] S. Normand et al., Discrimination methods between neutron and gamma rays for boron loaded plastic scintillators, Nucl. Instr. Methods A 484 (2002) 342.

[16] H.A. Yemam et al., Boron-rich benzene and pyrene derivatives for the detection of thermal neutrons, Sci. Rep. 5 (2015) 13401.

[17] N. J. Cherepy et al., Bismuth-and lithium-loaded plastic scintillators for gamma and neutron detection, Nucl. Instr. Methods A 778 (2015) 126.

[18] (a) N. Zaitseva et al., Pulse shape discrimination with lithium-containing organic scintillators, Nucl. Instr. Methods A 729 (2013) 747; (b) I. Sen et al., Thermal Neutron Scintillator Detectors Based on Poly (2-Vinylnaphthalene) Composite Films, IEEE Trans. Nucl. Sci. 58 (2011) 1386.

[19] R.D. Breukers et al., Transparent lithium loaded plastic scintillators for thermal neutron detection, Nucl. Instr. Methods A 701 (2013) 58.

[20] A.N. Mabe, Transparent lithium-6 based polymer scintillation films containing a polymerizable fluor for neutron detection, Radiat. Meas. 66 (2014) 5.

[21] Z.W. Bell et al., Organic scintillators for neutron detection, Proc. SPIE 4784 (2002) 150.

[22] L. Ovechkina et al., Gadolinium loaded plastic scintillators for high efficiency neutron detection, Phys. Procedia 2 (2009) 161.

[23] A.I. Bedrik et al., Plastic scintillator with gadolinium phenylpropionate, Funct. Mater. 18 (2011) 470. [24] R. Coulon et al., Dispositif de detection de neutrons thermiques et dispositif de comptage de neutrons thermiques associe, French Patent application, FR1460266, 2014. 
[25] J. Dumazert et al., Gadolinium-loaded plastic scintillators for thermal neutron detection and counting using photon response compensation, J. INST. (2015), Submitted.

[26] R. Voltz and G. Laustriat, Radioluminescence des milieux organiques I. Étude cinétique, J. Phys. France 29 (1968) 159.

[27] F.D. Brooks et al., Pulse shape discrimination in a plastic scintillator, IRE Trans. Nucl. Sci. NS7 (1960) 35.

[28] G.H.V. Bertrand et al., Pulse shape discrimination between (fast or thermal) neutrons and gamma rays with plastic scintillators: State of the art, Nucl. Instr. Methods A 776 (2015) 114.

[29] (a) F.P. Doty et al., Doped luminescent materials and particle discrimination using same, PCT Patent Appplication WO2011/060085, 2011; (b) P.L. Feng et al., Spectral- and Pulse-Shape Discrimination in Triplet-Harvesting Plastic Scintillators, IEEE Trans. Nucl. Sci. 59 (2012) 3312.

[30] P.N. Zhmurin et al., Plastic scintillator for pulse shape neutrons and gamma quanta discrimination, Radiat. Meas. 62 (2014) 1.

[31] M. Hamel et al., A fluorocarbon plastic scintillator for neutron detection: Proof of concept, Nucl. Instr. Methods A 768 (2014) 26. 